\title{
CARACTERÍSTICAS DA INDÚSTRIA PAULISTA NOS ANOS 90: EM DIREÇÃO A UMA CITY REGION?
}

\author{
Miguel Matteo \\ Universidade Estadual de Campinas
}

\author{
Jorge Ruben Biton Tapia \\ Universidade Estadual de Campinas
}

\begin{abstract}
RESUMO
A literatura internacional que discute as transformações provocadas pela globalização econômica, difusão das novas tecnologias da informação sobre paises, territórios e empresas tem apresentado algumas hipóteses que sustentam a emergência de novas configurações econômicas e territoriais chamadas ora de global city ora de city region. Elas refletem uma nova dinâmica baseada em redes de atores envolvidos em intensos fluxos de conhecimento e tecnologia e em uma progressiva capacidade de aprendizado institucional. Neste trabalho discutimos essas hipóteses à luz da experiência da economia paulista, procurando pensar a possibilidade ou não de assimilar o processo de reconcentração ampliada aos conceitos de global city e city region. Além dos enfoques mencionados, examinamos e apoiamo-nos, em termos teóricos, nas proposições dos autores filiados à escola regulacionista. A partir da leitura crítica dessas correntes, desenvolvemos a concepção de que, justamente devido às mudanças ocorridas na economia do estado de São Paulo nos anos noventa, houve um reforço da concentração espacial da indústria, a qual, embora apresente alguns aspectos associados às configurações econômicas espaciais denominadas de city regions, têm marcadas e importantes diferenças. Por isso, esse movimento de concentração ampliada, marcado pela forte predominância da região metropolitana de São Paulo (aí incluída a região do $A B C$ ) e as regiões que compõem o seu entorno (Campinas, São José dos Campos, Santos e Sorocaba), não pode ser caracterizado como uma dinâmica regional conectada com redes de cidades globais e desarticulada do restante da economia brasileira. Também, diferentemente do que afirma a literatura internacional que discute a emergência das cidades globais, não associamos as mudanças mencionadas a uma virtual substituição do setor secundário pelo terciário.
\end{abstract}

PALAVRAS-CHAVE: distribuição espacial da indústria; indústria paulista; reestruturação produtiva; city region; global city.

\section{INTRODUÇÃO}

$\mathrm{Na}$ agenda das transformações econômicas recentemente ocorridas no Brasil, ocupam um lugar de destaque a substituição da indústria pelo terciário que estaria ocorrendo em São Paulo, e a dinâmica inter-regional associadas ao movimento do capital no espaço - embora por vezes certas afirmações sejam difundidas sem a necessária afinidade com os dados empíricos disponíveis.

Este texto procura refletir sobre algumas dessas transformações, retomando, sob ótica diversa, alguns dos mesmos problemas levantados por Araújo (2001). Segundo a autora, "a RMSP [região metropolitana de São Paulo] deixou de ser predominantemente industrial e passou a se caracterizar como uma metrópole de serviços pro- dutivos, exatamente porque se mantém como a principal região industrial do país" (ARAÚJO, 2001, p. 10; grifos no original).

A indústria metropolitana paulista, nos anos 90 , passou por um intenso processo de transformação, que se coadunou com as mudanças decorrentes das características do capitalismo contemporâneo. Houve uma reestruturação industrial, baseada em novos paradigmas de produtividade $\mathrm{e}$ competividade, que fazem que a indústria da RMSP continue sendo o fator dinâmico da indústria paulista e nacional.

Outro ponto principal objeto desta discussão refere-se aos impactos do processo de globalização capitalista na dinâmica inter-regional brasileira, incluindo-se aí as mudanças em curso no núcleo 
industrial mais dinâmico, o estado de São Paulo (PACHECO, 1996). Cabe também analisar as trajetórias de localização das indústrias no estado, que passou por um processo de desconcentração nos anos 70 e 80 (tanto em relação a outras regiões do país, como da região metropolitana de São Paulo em direção ao interior do estado), mas que foi freado, ou mesmo revertido, em alguns setores, nos anos 90 .

Em São Paulo, a partir dos anos 30, ocorreu um crescimento diversificado de sua agricultura e de sua indústria, iniciando o processo de integração do mercado nacional. A partir daí sua indústria cresceu a um ritmo intenso, com médias superiores à nacional, concentrando parcelas crescentes do PIB nacional (cf. CANO, 1997).

Entre 1970 e 1985 começa, com a maturação da matriz industrial brasileira, um processo de desconcentração da indústria paulista, com a implantação de pesados investimentos fora do estado (hidroelétricas, siderúrgicas, químicos e petroquímicos) ou para regiões fora do espaço metropolitano. A crise na produção industrial no final desse período afetou com maior intensidade a indústria paulista, incrementando o processo de desconcentração.

A partir daí, contudo, houve um arrefecimento do processo: a forma como vem se dando a inserção da economia brasileira no mercado globalizado e a política de atração de investimento direto estrangeiro reforçam as assimetrias existentes entre as regiões, privilegiando aquelas que apresentam maiores vantagens competitivas (SASSEN, 1994; CASTELLS, 1995; SCOTT, 1996; COMPANS, 1999). Esse quadro, combinado com a ausência de políticas regionais de âmbito nacional, parece reforçar a tendência a uma concentração espacial.

Evidentemente, neste trabalho não é possível tratar de maneira detalhada o estado da arte do debate brasileiro em torno dos temas mencionados acima. Assim, a estratégia escolhida para a exposição será enunciar de maneira estilizada os principais argumentos, sem a preocupação de maior explicitação dos autores.

A literatura internacional que discute as transformações provocadas pela globalização econômica e a difusão das novas tecnologias da informação sobre países, territórios e empresas tem apresentado algumas sugestões que permitem rediscutir o binômio concentração-desconcentração. São examinadas as proposições dos autores que trabalham com os conceitos de cidades globais, city regions e com a escola regulacionista.

A partir da leitura crítica dessas correntes desenvolvemos como argumento central a concepção de que, justamente devido às mudanças ocorridas na economia do estado de São Paulo nos anos noventa, houve um reforço da concentração espacial da indústria, a qual, embora apresente alguns aspectos associados às configurações econômicas espaciais denominadas de city regions, têm marcadas e importantes diferenças.

Por isso, esse movimento de concentração ampliada, marcado pela forte predominância da região metropolitana de São Paulo (aí incluída a região do $\mathrm{ABC}$ ) e as regiões que compõem o seu entorno (Campinas, São José dos Campos, Santos e Sorocaba) não pode ser caracterizado como uma dinâmica regional conectada com redes de cidades globais e desarticulada do restante da economia brasileira. Também, diferentemente do que afirma a literatura internacional que discute a emergência das cidades globais e das city regions, não associamos as mudanças mencionadas a uma virtual substituição do setor secundário pelo terciário (tampouco houve um declínio da indústria paulista no conjunto da economia do Brasil), nem consideramos que a metrópole possa ser definida como um nó de uma economia internacionalizada, sem qualquer vínculo com o país de que faz parte.

$\mathrm{Na}$ análise da realidade brasileira, tomamos como referência a situação da indústria no estado de São Paulo, em particular a da RMSP, tendo como referência o ano de 1996, apoiando-nos no amplo e cuidadoso levantamento realizado pela Fundação SEADE, em sua Pesquisa da atividade econômica paulista (PAEP) ${ }^{1}$.

Duas ordens de fatores parecem explicar esse movimento de constituição de uma metrópole com novas características. A primeira, de natureza mais geral, está associada à estratégia de inserção internacional adotada pelo Brasil ao longo da década, à política de incentivo ao investimento estrangeiro direto e ao abandono de políticas regionais de âmbito nacional. A segunda ordem liga-se aos

\footnotetext{
1 A respeito do desenvolvimento metodológico dessa pesquisa e a conceituação das variáveis utilizadas, leia-se SEADE (2000); uma versão mais completa pode ser encontrada em SEADE (1999).
} 
fatores de atração locacional, característicos dos 90, como a densidade da rede urbana, da infraestrutura viária dessas regiões e a intensidade dos fluxos associada à redução dos custos de transporte propiciada pela localização em áreas próximas à RMSP, que se somam à proximidade do grande mercado consumidor da metrópole, formando uma densa rede de serviços altamente sofisticados, existentes exatamente devido à intensa atividade industrial, e que fornecem, por sua vez, uma potente alavanca para seu ulterior desenvolvimento.

O trabalho está organizado em cinco seções. Na primeira, são discutidas as principais proposições da literatura internacional, procurando identificar sua possível contribuição teórica para a interpretação da trajetória da economia paulista da década de noventa. Na segunda, apresentamos as principais características da indústria paulista na década de noventa. Na terceira, examinamos a evolução da indústria a partir da sua distribuição espacial, sublinhando o caráter concentrado da mesma. A seguir, na quarta seção, examinamos a dinâmica dos investimentos industriais, incluindose aí, além dos dados fornecidos pela PAEP, aqueles do Guia de Investimentos do Estado de São Paulo (SEADE, s/d). Finalmente, a título de conclusões, retomamos os principais resultados do trabalho.

\section{BREVE ESCORÇO SOBRE A BIBLIOGRA- FIA INTERNACIONAL}

De maneira estilizada, do ponto de vista dos objetivos deste artigo, a literatura internacional mais recente sobre globalização e transformações econômicas regionais pode ser agrupada em três grandes vertentes. A primeira delas, associada à noção de cidades globais, atém-se à crescente terceirização das principais aglomerações, que estariam transitando de um mundo industrial a uma sociedade dominada por serviços altamente intensivos em tecnologia (financeiros, de informação, de entretenimento etc.). A segunda, também chamada de "californiana", de marcante orientação neo-institucionalista, dá ênfase à existência de city regions globais, que configuram estruturas industriais concentradas (sobretudo intensi-

\footnotetext{
2 Parece mais sensata a tradução de governance para o espanhol: nessa língua, a palavra é traduzida pela expressão "formas de articulação do poder".
}

vas em tecnologia), articuladas globalmente por seus arranjos de governança ${ }^{2}$. A terceira corrente, de matriz européia, diferentemente da primeira, inscreve-se no campo da análise regulacionista e, embora não desconsidere a relevância das grandes metrópoles e de seus vínculos como importantes loci da economia globalizada, confere um papel relevante aos estados nacionais nos processos de reestruturação produtiva e espacial que ocorrem nessas regiões.

A primeira corrente acadêmica identificada teve origem nos trabalhos fundadores de Peter Hall (1966), John Friedmann (FRIEDMANN, 1986; FRIEDMANN \& WOLFF, 1982) e Saskia Sassen (1991). Enquanto Peter Hall chamou atenção para o planejamento e a gestão no uso do solo urbano, John Friedmann dirigiu sua atenção para as global network of cities e Saskia Sassen para as global cities como centros de decisão e espaços de polarização social.

Peter Hall, um dos principais expoentes dessa corrente, define cidade mundial como centro de poder político (nacional e internacional) e de órgãos governamentais; centro de negócios nacionais e internacionais, atuando como entreposto para seu país e países vizinhos; centro de bancos, seguros e outros serviços financeiros; centro de atividades profissionais avançadas de todos os tipos, como medicina, direito, educação superior e aplicação de conhecimento científico à tecnologia; centro de informação e difusão, através de editoras e mídia de massas; centro de consumo conspícuo, de bens de luxo para a minoria e de produtos de massa, e centro de artes, cultura e entretenimento.

Embora admita que cidades desse tipo sempre existiram, Hall argumenta que elas incrementaram sua centralidade com o fenômeno da globalização: com a informatização da economia e com a progressiva mudança, nas economias avançadas, de bens de produção para manejo de informação, a grande maioria da força de trabalho não lida mais com produtos materiais. Castells (1996), por sua vez, caracteriza esse fato como uma mudança econômica fundamental, um momento equivalente ao da transformação da economia agrária em industrial, nos séculos XVIII e XIX.

O núcleo do dinamismo das cidades mundiais estaria intrinsecamente ligado ao papel central desempenhado pelas sedes das grandes corporações multinacionais. Como sublinha Friedmann (1986), 
é justamente através das corporações multinacionais que as cidades globais inserem-se nos circuitos globais do capital. O papel central das grandes empresas multinacionais também explicaria o fato de as cidades globais terem externally driven dynamics e porque elas apresentam uma configuração complexa ${ }^{3}$, na qual coexistem uma expressiva volatilidade econômica, a presença de redes sociais reflexivas densas em informação, um espírito cosmopolita convivendo com uma crescente polarização social e diversidade cultural, em especial associada ao recrudescimento dos fluxos migratórios.

Ao destacar as cidades mundiais como centros de decisão no mundo do capitalismo globalizado, Sassen observa que a produção, graças à tecnologia, pode ser dispersa, desvinculandose assim os negócios e os serviços da produção. Para essa autora, a dispersão da produção, incluindo a internacionalização, contribuiu para o crescimento de nós de serviços centralizados para o gerenciamento e para a regulação do novo espaço econômico. O peso da atividade econômica deslocou-se de lugares baseados na produção para centros financeiros e de serviços altamente especializados, que existem em pequeno número e são chamados de "cidades globais".

Essas cidades são centros de serviços financeiros e centros de decisão de grandes empresas (algumas são também sede de poder governamental). Por serem centros, elas atraem serviços altamente especializados (direito comercial, publicidade, serviços de relações públicas), também crescentemente globalizados e relacionados com essa centralidade. Uma possível formulação a partir da dinâmica das cidades globais é da emergência de metrópoles de serviços em substituição às antigas metrópoles industriais.

A proposição teórica básica da corrente californiana é que a combinação entre fortes pressões no sentido da metropolização ou aglomeração das atividades econômicas e a globalização da concorrência econômica teria produzido um novo tipo de dinâmica de desenvolvimento ou de crescimento econômico. Os atores decisivos desse novo fenômeno seriam regiões específicas, as cha-

\footnotetext{
3 Uma estrutura ou sistema é complexo quando suas propriedades ou características não podem ser explicadas satisfatoriamente pela compreensão de suas partes.
}

madas city regions, que passariam a ter uma influência crescente no mundo globalizado.

Como reconhecem Storper et alii (2000) a corrente californiana compartilha algumas hipóteses com autores da corrente das global cities, mas apresenta duas diferenças fundamentais. $\mathrm{Na}$ verdade, o conceito de city region seria uma proposta de ampliação da interpretação e da própria agenda de pesquisa original de Hall, Friedman e Sassen. No que consiste exatamente esse movimento? Basicamente, a principal contribuição estaria em indicar a emergência dessas novas configurações político-econômicas espaciais, esses novos "nós" essenciais na economia globalizada. Assim, as city regions, como unidades de análise, distinguem-se do conceito clássico de "cidade", considerado muito restrito para o entendimento da crescente interdependência de múltiplas redes de atividades econômicas organizadas em configurações territoriais ampliadas, tais como o länder, províncias, municipalidades, áreas metropolitanas etc.

Portanto, a primeira diferença é que elas abrangem uma relativa diversidade de configurações, podendo ser desde uma grande metrópole, um grande espaço produtivo ou mesmo uma rede de pequenas e médias cidades (como na região da Emilia Romagna, na Itália). O importante é que essas city regions sejam nós espaciais essenciais para a economia global.

Para Scott, a compreensão da dinâmica das economias regionais é melhor quando essa é vista como um conjunto de relações, que constituem processos reflexivos e não como os enfoques tradicionais, como "o resultado de complexas forças econômicas, economias externas e de aglomeração" (SCOTT, 1997, p. 31). Assim, o autor defende como alternativa teórica conceituar a economia como um sistema de relações ao invés da imagem tradicional de máquina ou mecanismo. Esse deslocamento teórico equivale a privilegiar como núcleo da análise as dimensões de coordenação e de troca de informações entre os agentes econômicos e a considerar o processo de acumulação como ancorado em ativos relacionais e materiais simultaneamente.

Como Scott apresenta a dinâmica das grandes cidades no mundo globalizado? Analisando as interrelações entre interesses, necessidades organizacionais e territórios, o autor sublinha que a adoção de políticas de desregulamentação financeira e 
ampla liberdade de investimentos não esgota as condições necessárias para a acumulação flexível. Esta requer também mais do que um movimento livre de entrada e saída, já que faz parte das condições da acumulação flexível do capital global um tipo de global locational tournament entre países. Portanto, diz Scott, os regimes de acumulação baseados fortemente apenas na flexibilidade e na desregulamentação ignoram a importância dos fatores territoriais e de proximidade dinamizados pelas redes e relações que permitem um uso mais eficiente dos recursos disponíveis, aumentando a lucratividade das empresas.

A análise proposta por Scott tem claras implicações sobre a agenda de pesquisa. A nova dinâmica das economias regionais exige uma nova agenda de pesquisa que examine as bases, convenções e relações de aprendizado de empresas e regiões para reforçar os ativos relacionais baseados nos recursos locacionais de ambos. Noutras palavras, as probabilidades de êxito das estratégias regionais de longo prazo dependerão muito da assunção de que "what firms do is inherently tied up with what regions do, and vice-versa" (idem, p. 299).

Surge então a segunda grande diferença entre as duas correntes: essas regiões, para Scott, passam a ser consideradas o motor da economia global, já que, num novo paradigma tecnológico, a grande concentração mitiga os custos de transação, aumenta os efeitos de informação e flexibilidade, incentiva graus crescentes de criatividade e inovação devido à alta qualificação da força de trabalho e fornece uma grande variedade de fornecedores e de oportunidades de negócios. Dessa forma, um mosaico de grandes cidades-regiões constitui uma das principais redes estruturais da nova economia global, às quais essas economias e regiões ligam-se em redes flexíveis de firmas que cooperam e competem num crescente e extenso mercado.

Ao contrário do que sugerem visões puramente normativas e apologéticas da globalização econômica, a atual configuração da economia capitalista não aponta para uma descentralização e desconcentração das atividades econômicas, nem para o fim inevitável da atividade industrial. Não obstante o inegável e acentuado declínio dos custos de transportes e de comunicações, ainda temos um mundo organizado ao redor de grandes regiões urbanas (ao invés de um padrão mais difuso de localização). A novidade não está, portanto, na simples concentração geográfica ou territorial das atividades econômicas, mas sim na morfologia dessas e nos elementos geradores da sua dinâmica.

No entanto, a globalização e a reestruturação econômica provocam alguns efeitos na geografia social dessas regiões: um aumento da heterogeneidade cultural e demográfica; uma pronunciada mudança na morfologia espacial das cidadesregiões globais e uma tendência a aumentar o fosso entre os ricos e os pobres em termos econômicos, sociais e espaciais.

A globalização intensifica e estimula o crescimento de ocupações de altos salários, mas também a proliferação de trabalhos marginais e desqualificados, aumentando a segmentação social nas cidades-regiões. A ausência de condições de governança no poder local provoca a substituição do poder público por organizações não-governa-mentais, para a população pobre, com as quais não há garantia de formas de proteção social. Para a população rica, há a privatização de serviços públicos, e mesmo do espaço público.

Ou seja, não basta que as regiões sejam plataformas eficientes de vantagens competitivas; se carecerem de estruturas institucionais de governança, não será possível assegurar a ordem social nem manter a virtuosidade da atividade econômica.

Outro tema incontornável é o dos papéis dos estados nacionais e das estruturas de governança. Aqui a formulação tanto do enfoque das cidades globais como das city regions é problemática, embora a maioria dos autores rejeite a tese do declínio do Estado-nação e sustente inclusive um reforço do seu papel como mecanismo de mediação entre as forças globais de mudança e as diferentes formações nacionais.

Na verdade, o papel dos estados nacionais está limitado ao de aliado ou de mecanismo de mediação com as forças da globalização. Vejamos os exemplos utilizados pelos principais autores. De um lado, teríamos os países com estruturas políticas mais descentralizadas; neste caso as instâncias de governo mais importantes na articulação das global cities ou city regions com os elos da economia globalizada são a regional e a local. De outro lado, os países com maior tradição de intervenção do governo central ou nacional: aqui a competividade das global cities ou city regions 
apóia-se em parte nas ações do poder central por meio das instâncias subnacionais. Em qualquer das situações analisadas, a preponderância é das instâncias subnacionais, ficando ao Estado nacional o papel de aliado do desenvolvimento local.

Essa perspectiva é reafirmada se examinamos a temática das estruturas de governança. Em termos gerais, a natureza da governança dependerá da configuração específica da global city ou city region; no entanto, alguns elementos são comuns às estruturas de governança. De um lado, haveria o conjunto de ações pró-ativas voltadas para fornecer bens públicos (educação, treinamento profissional, acesso a informações técnicas a pequenas e médias empresas etc.) e de estímulo e favorecimento de sinergia entre os atores públicos e privados conectados em diferentes redes. De outro, um conjunto de ações compensatórias voltado para enfrentar os problemas sociais gerados ou intensificados pelo movimento de globalização capitalista. Os movimentos migratórios, a exclusão de grupos de trabalhadores com pouca qualificação, esses deslocados pelo novo paradigma de produção flexível, os níveis elevados de desemprego (em especial entre os jovens), a violência urbana, comporiam a paisagem noir de um mundo pós-fordista.

Com a abertura dos fluxos comerciais, emerge uma nova organização espacial que consiste, acima de tudo, em uma hierarquia de escalas territoriais da atividade econômica e de relações de governança, que variam do global ao local, havendo um deslocamento dos níveis de definição das políticas, de um lado, para um nível supranacional, e de outro, para níveis de operação locais ou regionais. Com isso, ganham impulso as formas de organização política e econômica de base regional, representadas pelas cidades-regiões, que não podem ser entendidas senão em relação à complexa hierarquia de escalas territoriais interpenetrantes.

Nessa nova estrutura de governança, os papéis reservados aos estados nacionais confundemse na maioria das vezes com políticas subnacionais de amparo às city regions, ficando a complexa temática do Estado nacional no plano da economia nacional negligenciada pelos estudiosos.

Para Dunford e Kafkalas (1992), representantes da escola regulacionista, o papel das grandes aglomerações também tem importância fundamental na economia globalizada: face à incerteza associada à crise industrial, os grandes grupos econômicos desenvolveram novas estratégias produtivas, cujas metas principais eram reduzir os seus custos de produção e aumentar sua flexibilidade em relação ao seu ambiente econômico. Para isso, seria necessário que essas estratégias envolvessem uma lógica de desintegração produtiva e uma cooperação interfirmas. Novas formas multidivisionais foram desenvolvidas em lugar de formas hierárquicas, mas combinando uma certa descentralização de atividades operacionais com uma acentuada centralização de poder econômico.

A reestruturação produtiva implica, assim, o renascimento de economias regionais, redes locais e processos de desenvolvimento endógenos, o que leva a uma interpretação de perspectivas locais no contexto da geografia das grandes corporações transnacionais, estabelecendo uma contradição entre a globalização e a localização de atividades econômicas.

Se as forças de mercado prevalecem, novos investimentos tenderão a ser direcionados para as regiões mais avançadas, porque elas oferecem maiores vantagens técnicas, sociais e institucionais, infra-estrutura básica para uma produção sofisticada e intensiva em conhecimento. As metrópoles possuem melhor qualificação da força de trabalho, estratégias de integração econômica e o desenvolvimento de redes de informação.

São desenvolvidas nessas regiões novas formas de governança, estabelecendo políticas urbanas empresariais, onde o Welfare State confundese com o sucesso econômico, e onde o tradicional welfare keynesiano desaparece com a emergência do Estado neoliberal minimalista.

A realocação das atividades de gerenciamento do território e a desregulação múltipla são apropriadas para a mobilização das potencialidades locais e a reprodução estável sob condições de integração local e fragmentação local e regional; ao mesmo tempo, objetivos sociais e ambientais não são mais uma necessidade (no nível nacional) de uma distribuição igualitária.

A conclusão dos autores é que, sem uma regulação supra-regional e uma descentralização organizacional, não há uma perspectiva real de estabilidade macroeconômica ou uma plena realização do potencial produtivo das novas tecnologias; ao contrário, o novo modelo de crescimento pro- 
voca uma divisão mais profunda na sociedade, gerando uma sociedade dual.

Amin e Robins (1994) fazem a crítica à escola californiana numa perspectiva de economia política mais ampla, a partir da natureza do desenvolvimento e da transformação que está experimentando o capitalismo. Segundo eles, os defensores do que eles consideram uma nova ortodoxia superestimam a importância das novas aglomerações industriais, conseqüência de uma propensão a amalgamar em uma única categoria processos e regiões muito diferentes, convertendo-a em símbolo de um novo espaço de acumulação, dentro de uma mudança de paradigma tecnológico (conforme Piore \& Sabel), que substitui a produção em massa pelo regime de especialização flexível (baseado em tecnologias e trabalhadores flexíveis, e novas formas de comunidades industriais). Mas Amin e Robins avaliam que:

1. a transformação estrutural (quer dizer, o deslocamento dos mercados de massa) sobre a qual se apóia o conjunto da teoria da especialização flexível e das economias locais, é duvidosa. Não estaríamos assistindo a uma maior diferenciação dos produtos ao invés da destruição dos mercados de massa?

2. Sobre a natureza das explicações que Piore e Sabel dão em relação à nova bifurcação industrial (industrial divide): seu marco psicológico (confiança, lealdade com a comunidade, solidariedade, identidade local) reflete, em certa medida, o desejo dos autores de evitar o determinismo tecnológico ou econômico. A linguagem da escolha individual está integrada em um discurso sobre os atores coletivos e a ação política. O marco atomista e individualista da teoria não pode combinar-se ou harmonizarse com uma perspectiva mais ampla de transformação estrutural e política. O enfoque de Piore e Sabel termina em uma insatisfatória mescla de determinismo e voluntarismo: "Uma oposição conceitual tão limitada [entre especialização flexível e produção em massa] constitui um princípio estruturante demasiado pobre para uma teoria do desenvolvimento e da mudança socioeconômica" (AMIN \& ROBINS, 1994, p. 133).

Há, portanto, uma negação, por parte da escola regulacionista, não do papel representado pelas regiões metropolitanas, mas da forma como elas articular-se-iam em uma pretensa rede internacional, independentemente dos estados nacionais de que fazem parte e, sobretudo, de um possível ingresso em uma nova era de produção flexível, na qual a base da aglomeração seria a maior possibilidade de mitigar os custos de transação dos bens intangíveis, enquanto as relações sociais e o papel do Estado nacional são remetidos a um plano diverso, que está fora do centro da análise econômica.

Em todas as vertentes de análise, entretanto, verifica-se que o papel destinado às grandes aglomerações urbanas no final do século XX não é o da sua inviabilidade como lugar para trabalhar ou viver, conforme antevisto por vastos setores da sociedade nos anos 60 e 70 . Ao contrário, uma das características dos processos contemporâneos é, no olhar de Veltz (1996), a crescente concentração territorial da economia, em favor notadamente das grandes metrópoles mundiais.

Com base nos novos papéis desempenhados pelas economias de escala e das externalidades (de tipo "neo-marshallianos"), nos quais se sobressai o aspecto de coordenação e integração entre as empresas e em que a concorrência não se dá apenas pelos preços, mas pela diferenciação, Veltz afirma que as metrópoles têm seu poder de atração aumentado sobre os consumidores e as firmas. Isso ocorre não somente graças à grande variedade de bens e serviços disponíveis, mas graças à diferenciação do mercado de trabalho, considerada uma das chaves da análise da concentração metropolitana atual, que reforça o papel das proximidades sociais. Segundo Veltz, "a questão dos liames espaciais entre fatores, recursos e operações produtivas não foi eliminado, mas subordina-se à questão mais ampla das relações sociais que permitem a cooperação e as formas espaciais" (VELTZ, 1996, p. 79).

Ainda segundo esse autor, é uma tarefa quase impossível traçar com clareza os limites entre a atividade industrial e a de serviços, uma vez que esta última tem uma forte dependência do setor secundário; além disso, muitas das atividades hoje desempenhadas por trabalhadores ocupados no setor terciário, até há pouco tempo eram-no no interior das indústrias, que passaram a terceirizar as atividades que não faziam parte de seus obje- 
tivos centrais.

\section{AS CARACTERÍSTICAS DA INDÚSTRIA DO ESTADO DE SÃO PAULO NOS ANOS NOVENTA}

A implementação de reformas estruturais e a revisão do modelo de desenvolvimento econômico e tecnológico nacional exigiram da indústria de transformação brasileira, nos últimos anos, esforços substanciais para adaptação ao novo ambiente regulatório e concorrencial. Para a indústria paulista em particular, caracterizada pelo seu elevado grau de integração produtiva e avançado parque tecnológico instalado, o processo de ajuste deu-se de maneira mais intensa que para outras regiões do país.

Embora as informações econômicas mais recentes apontem para a manutenção da importância da indústria paulista no cenário nacional, houve mudanças quantitativas e qualitativas que exigem um esforço de detalhamento, porque esse foi um período de mudanças organizacionais, tecnológicas e de condução da política macroeconômica. Grosso modo, em termos qualitativos cresceu o peso relativo dos setores intensivos em conhecimento e tecnologia em São Paulo (muito embora longe de expressar o virtuosismo do modelo das city regions), enquanto foram os setores intensivos em mão-de-obra os que sofreram os efeitos desse processo com maior impacto.

Como sabemos, a indústria brasileira vem passando, nos últimos 30 anos, por um processo de desconcentração regional de suas atividades, diminuindo a importância do eixo Rio-São Paulo, e expandindo seus limites para outros estados da federação (CANO, 1997). No caso de São Paulo, a desconcentração deu-se mais em relação ao município de São Paulo e à RMSP, favorecendo as regiões do interior do estado. Esse movimento teve como determinantes, dentre outros fatores, as políticas do governo federal, dos anos 70 e 80 , de direcionamento dos investimentos industriais para regiões periféricas da economia brasileira, de acordo com as diretrizes dos Planos Nacionais de Desenvolvimento (I e II).

Durante os anos 80, o processo de desconcentração ganhou impulso maior ao associar-se à crise recessiva que se instalou, atingindo de maneira mais expressiva o estado de São Paulo (que, na época, concentrava mais de dois terços da indústria nacional de bens de capital), dadas as relações mais intensivas de interdependência entre as divisões da indústria. Foi também nesse período que os investimentos federais em outros estados da federação (e no interior paulista) atingiram o seu grau de maturação.

No início dos anos 90 a indústria paulista apresentava, basicamente, os mesmos níveis de produção do início da década anterior. O novo ambiente macroeconômico marcado, de um lado, por uma rápida e pouco coordenada abertura e desregulamentação e, de outro lado, pelo comportamento errático da economia, aos quais se acoplou um movimento de reestruturação produtiva, estabeleceu novos parâmetros de funcionamento para as empresas industriais, implicando a racionalização das suas estruturas e a introdução de novas formas de gestão, com fortes impactos no emprego industrial.

Nos últimos anos dos noventa, com a consolidação do processo de abertura econômica, diferentes impactos puderam ser notados. É verdade que a estabilização econômica trouxe um novo alento à atividade produtiva, especialmente nos setores produtores de bens de consumo duráveis e não-duráveis, mas também alguns segmentos passaram a sofrer acirrada concorrência com produtos importados, o que promoveu retrações na sua produção física total e, conseqüentemente, refletiu-se em menores participações na estrutura produtiva paulista. Por outro lado, a concorrência interestadual por novos investimentos industriais, com a outorga de incentivos - também conhecida como guerra fiscal -, vem promovendo algumas alterações no quadro da distribuição espacial da indústria no território brasileiro.

Entretanto, essas transformações não levaram a um aprofundamento significativo da desconcentração, em termos de valor adicionado, como pareciam supor as tendências apontadas pela literatura na década de oitenta. Afinal, como mostram os resultados da Pesquisa Industrial Anual de 1996 e de 1999, da Fundação IBGE, ao comparar os dados levantados em campo com os do Censo Industrial de 1985, a participação da indústria paulista no Valor da Transformação Industrial do Brasil ficou praticamente estável, entre 1985 e 1996: passou de $48 \%$, em 1985, para 49,5\%, em 1996, e para $50 \%$ em 1999. Em termos de pessoal ocupado, contudo, a participação de São Paulo, que era de 47\% em 1985, caiu para 42\% em 1996 e para 38\% em 1999.

No grupo dos setores da indústria que sofreu 
perdas expressivas na sua participação estão fumo, calçados, metalurgia básica, fabricação de produtos de metal, máquinas e equipamentos, fabricação de material eletrônico, veículos automotores e móveis e indústrias diversas.

Se os setores que perderam participação tiveram uma redução expressiva de seus índices, para aqueles que aumentaram sua participação esse aumento foi igualmente expressivo. No grupo de setores que cresceu, no mesmo período, destacamos os setores de edição, impressão e reprodução de gravações, fabricação de minerais nãometálicos e de fabricação de equipamentos de informática. No caso dos demais setores da indústria, as variações na participação do VTI paulista em relação ao Brasil são pouco expressivas, inclusive em setores tradicionalmente importantes, como o alimentício e o químico.

Muito modesto foi, no mesmo período, o crescimento do pessoal ocupado na indústria paulista. Quando a participação é medida por essa variável, verifica-se que apenas quatro setores tiveram crescimento, ainda assim discretos - edição e impressão, minerais não-metálicos, equipamentos de informática e veículos automotores. Ao mesmo tempo, houve uma queda, por vezes acentuada, em todos os demais setores.

Esses dados parecem confirmar os resultados das pesquisas sobre a evolução do emprego na indústria paulista na década de noventa ${ }^{4}$, que apontam para o impacto negativo sobre o emprego, sobretudo industrial, da combinação de recessão prolongada com reestruturação produtiva e inserção internacional baseada na estabilidade do câmbio e estímulo à internacionalização da economia brasileira. Em consonância com o que aponta a literatura internacional, mesmo em patamares modestos, entre os maiores ganhos em termos de participação do VTI e até mesmo de pessoal ocupado, estão os setores intensivos em capital, tecnologia e conhecimento.

Os dados da PAEP mostram que, em 1996, a indústria paulista apresentava uma estrutura complexa, cujas principais divisões eram as de produ-

\footnotetext{
4 Por exemplo, a Pesquisa de Emprego e Desemprego (PED), realizada pela Fundação SEADE e pelo DIEESE (SEADE, s/d), e o Índice de Ocupação da FIESP (FIESP, $\mathrm{s} / \mathrm{d})$.

5 Uma análise da estrutura da economia paulista pode ser encontrada em Araújo (2000).
}

tos químicos, de alimentos, automobilística (inclusive o setor de autopeças), de máquinas e equipamentos e de edição, impressão e gravações, responsáveis por $55 \%$ de todo o valor adicionado pela indústria no estado de São Paulo e por $42 \%$ do pessoal ocupado 5 .

Cumpre sublinhar que, embora em termos gerais a composição da estrutura industrial paulista não apresente alterações substanciais em relação à revelada por antigas pesquisas do IBGE, há uma exceção interessante, que é a da indústria editorial e gráfica, que se tornou recentemente uma das cinco maiores do estado em termos de valor adicionado. Para evitar reduzir as razões desse desempenho a um efeito estatístico, convém separar nitidamente dois componentes. O primeiro diz respeito a uma alteração de ordem estatística introduzida em 1994 na Classificação Nacional da Atividade Econômica, que trouxe para o interior dessa divisão da indústria todas as atividades de edição e gravação de CDs (de música e de informática) e disquetes. O segundo está ligado ao efetivo crescimento da atividade editorial (jornais, revistas e livros de material didático, sobretudo) - mas essa é também uma mudança qualitativa recente das atividades de música, informática e disquetes, cuja produção evoluiu positivamente.

Por outro lado, o complexo metal-mecânico tem mantido um lugar importante no conjunto da economia paulista, sobretudo em valor adicionado, apesar dos impactos negativos produzidos pela trajetória errática da economia sobre a divisão de máquinas e equipamentos ${ }^{6}$. Enquanto isso, as divisões como a química e alimentos - a primeira com maior grau de concentração na metrópole e entorno, e a segunda valendo-se da integração com a agropecuária - respondem por mais de um quarto do valor adicionado do estado e por quase um quinto dos empregos.

Em nítido contraste com o complexo metalmecânico, químico e alimentício, as indústrias de produtos de metal, têxtil e do vestuário têm pequena expressão em termos de valor adicionado,

\footnotetext{
6 Saliente-se que a participação dessa divisão na estrutura industrial brasileira sofreu uma acentuada queda entre 1985 e 1996, motivada pelo impacto da paridade cambial, transformando as unidades de empresas transnacionais em revendedoras de máquinas importadas; o único estado em que há uma evolução positiva nesse setor é o Rio Grande do Sul, graças à fabricação de implementos agrícolas.
} 
exprimindo uma baixa produtividade, embora seja expressiva sua participação no número de unidades e de pessoal ocupado.

Confirmando o que foi dito anteriormente, a evolução das indústrias ligadas ao uso intensivo de conhecimento e tecnologia indica mudanças qualitativas, que pouco se refletem em termos quantitativos. Nesse sentido, é interessante notar a pequena participação das divisões industriais tidas como fundamentais no novo paradigma tecnológico, chamadas de "intensivas em conhecimento", ou seja, as de material elétrico e tele- comunicações, de material eletrônico, de equipamentos médicos, óticos, de precisão e automação e de máquinas de escritório e equipamentos de informática, que, somadas, representam $7 \%$ do pessoal ocupado e $9 \%$ do valor adicionado da indústria paulista. Ao mesmo tempo, essas divisões, que têm relevância estratégica para a inserção num novo paradigma tecnológico, têm uma pequena relevância econômica na estrutura industrial paulista, mas concentram mais da metade da produção brasileira no setor, de acordo com os dados da Pesquisa Industrial Anual, de 1996.

TABELA 1 - Distribuição do número de unidades, pessoal ocupado e valor adicionado, segundo divisão da indústria, no estado de São Paulo, em 1996 (em \%)

\begin{tabular}{|c|c|c|c|}
\hline Divisão da indústria & $\begin{array}{l}\text { Número de } \\
\text { unidades }\end{array}$ & $\begin{array}{l}\text { Pessoal } \\
\text { ocupado }\end{array}$ & $\begin{array}{c}\text { Valor } \\
\text { adicionado }\end{array}$ \\
\hline Produtos químicos & 5,1 & 7,1 & 14,1 \\
\hline Alimentos e bebidas & 12,1 & 12,4 & 12,9 \\
\hline Automobilística & 2,6 & 8,3 & 11,4 \\
\hline Máquinas e equipamentos & 6,6 & 9,4 & 9,9 \\
\hline Edição, impressão, gravações & 5,9 & 4,4 & 6,9 \\
\hline Borracha e plástico & 6,1 & 6,6 & 5,7 \\
\hline Produtos de metal (exclusive máquinas e equipamentos) & 9,5 & 7,5 & 5,2 \\
\hline Têxtil & 5,0 & 6,8 & 4,4 \\
\hline Minerais não-metálicos & 6,4 & 4,9 & 4,0 \\
\hline Metalurgia básica & 2,9 & 3,7 & 3,9 \\
\hline Material eletrônico e equipamentos de comunicação & 1,1 & 2,0 & 3,7 \\
\hline Papel e celulose & 2,3 & 3,3 & 3,6 \\
\hline Materiais elétricos & 2,7 & 3,6 & 3,4 \\
\hline Vestuário e acessórios & 14,0 & 6,6 & 2,4 \\
\hline Móveis e indústrias diversas & 8,0 & 4,8 & 2,2 \\
\hline Refino de petróleo e álcool & 0,3 & 1,4 & 1,2 \\
\hline Equipamentos médicos, óticos, de automação e precisão & 1,3 & 1,1 & 1,1 \\
\hline Couro e calçados & 3,4 & 3,0 & 1,0 \\
\hline Fumo & 0,0 & 0,1 & 0,9 \\
\hline Outros equipamentos de transporte & 0,5 & 0,8 & 0,7 \\
\hline Indústria extrativa & 1,6 & 0,8 & 0,6 \\
\hline Madeira & 2,2 & 1,1 & 0,5 \\
\hline Máquinas de escritório e equipamentos de informática & 0,3 & 0,3 & 0,5 \\
\hline TOTAL & 100,0 & 100,0 & 100,0 \\
\hline
\end{tabular}

Fonte: Fundação SEADE. Pesquisa da Atividade Econômica Paulista. PAEP.

O dinamismo da estrutura industrial do estado de São Paulo é, visto pelo ângulo do porte de suas unidades, fortemente concentrado na grande indústria: $83 \%$ do valor adicionado pela atividade industrial paulista são produzidos nas unidades com mais de 100 pessoas ocupadas, sendo 58\% naquelas com mais de 500 empregados. Essa concentração é ligeiramente atenuada quando se ana- 
lisa o pessoal ocupado e inverte-se quando se analisa o número de unidades locais: $82 \%$ das unida-

des possuem menos de 100 pessoas ocupadas ${ }^{7}$.

TABELA 2 - Distribuição do número de unidades, pessoal ocupado e valor adicionado, segundo faixas de pessoal ocupado, no estado de São Paulo, em 1996 (em \%)

\begin{tabular}{|l|r|r|r|}
\hline Faixas de pessoal ocupado & $\begin{array}{c}\text { Número de unidades } \\
\text { locais }\end{array}$ & Pessoal ocupado & Valor adicionado \\
\hline 5 a 29 & 64,9 & 17,0 & 7,6 \\
\hline 30 a 99 & 17,3 & 16,7 & 9,8 \\
\hline 100 a 249 & 7,0 & 15,4 & 12,2 \\
\hline 250 a 499 & 3,4 & 12,5 & 12,1 \\
\hline 500 e mais & 7,4 & 38,3 & 58,2 \\
\hline TOTAL & 100,0 & 100,0 & 100,0 \\
\hline
\end{tabular}

Fonte: Fundação SEADE. Pesquisa da Atividade Econômica Paulista. PAEP.

A interiorização do desenvolvimento (CANO, 1988; 1992; NEGRI, 1988), em consonância com o que já vinha acontecendo nas décadas anteriores, ocorre cada vez mais concentrada espacialmente, localizando-se sobretudo num raio de aproximadamente $150 \mathrm{~km}$ a partir do centro da RMSP, abrangendo as regiões administrativas de Campinas, São José dos Campos, Santos e Sorocaba, que, em conjunto com a RMSP, representam $82 \%$ do total de unidades industriais, $85 \%$ do pessoal ocupado e $90 \%$ do valor adicionado da indústria do estado.

Tabela 3 - Distribuição do número de unidades, pessoal ocupado e valor adicionado, segundo região administrativa do estado de São Paulo, em 1996 (em \%)

\begin{tabular}{|l|r|r|r|}
\hline \multicolumn{1}{|c|}{ Região administrativa } & \multicolumn{1}{c|}{$\begin{array}{c}\text { Número de } \\
\text { unidades }\end{array}$} & Pessoal ocupado & Valor adicionado \\
\hline Metropolitana de São Paulo & 56,9 & 56,8 & 60,4 \\
\hline Município de São Paulo & 40,3 & 33,0 & 33,1 \\
\hline Municípios do ABC & 6,6 & 11,3 & 13,8 \\
\hline Demais municípios da RMSP & 9,9 & 12,5 & 13,5 \\
\hline Campinas & 14,8 & 16,9 & 16,1 \\
\hline São José dos Campos & 3,2 & 4,4 & 6,5 \\
\hline Sorocaba & 5,8 & 6,0 & 5,2 \\
\hline Ribeirão Preto & 2,1 & 2,3 & 2,2 \\
\hline Santos & 1,3 & 1,1 & 2,1 \\
\hline Central & 2,4 & 2,4 & 1,9 \\
\hline Bauru & 2,1 & 2,6 & 1,4 \\
\hline São José do Rio Preto & 3,2 & 2,0 & 1,0 \\
\hline Barretos & 0,6 & 0,5 & 0,8 \\
\hline Franca & 2,1 & 1,5 & 0,6 \\
\hline Araçatuba & 1,6 & 1,4 & 0,6 \\
\hline Marília & 2,0 & 1,2 & 0,6 \\
\hline Presidente Prudente & 1,4 & 0,8 & 0,4 \\
\hline Registro & 0,4 & 0,2 & 0,2 \\
\hline TOTAL & 100,0 & 100,0 & 100,0 \\
\hline Fonte: Fundaçäo SEADE & & $P A E P$ & \\
\hline
\end{tabular}

Fonte: Fundação SEADE. Pesquisa da Atividade Econômica Paulista. PAEP.

\footnotetext{
7 Uma análise da diferenciação das empresas com portes diversos pode ser encontrada em Assembléia Legislativa do Estado de São Paulo (2000).
} 
A trajetória de desconcentração metropolitana ocorrida nas décadas de setenta e oitenta foi largamente determinada pelos "custos de aglomeração", expressos na saturação da infra-estrutura de transporte, pela valorização imobiliária, pelas restrições impostas pela legislação ambiental, assim como pelos maciços investimentos estatais em infra-estrutura energética e de transportes, pelo crescimento da agroindústria da cana (Proálcool) e da laranja (voltado à exportação), reconhecidamente fatores indutores do crescimento industrial no interior paulista. Esse movimento de desconcentração foi ainda ampliado na década de oitenta, em conseqüência da crise vivida pelo aparato produtivo da metrópole.

A esses fatores, nos anos noventa, entretanto, somaram-se novos na definição da localização industrial das empresas, levando a que as escolhas recaiam preferencialmente nas regiões administrativas situadas no entorno da RMSP. Além da proximidade com o grande mercado consumidor da metrópole constituir-se em um dos principais determinantes da localização de indústrias nessas regiões, a densidade da malha urbana, da infraestrutura viária dessas regiões e a intensidade dos fluxos, associados à redução dos custos de transporte propiciada pela localização em áreas próximas à RMSP, acabaram criando uma extensa região econômica (MATTEO, 1990).

\section{A DISTRIBUIÇÃO REGIONAL DAS PRIN- CIPAIS DIVISÕES DA INDÚSTRIA NOS NOVENTA}

$\mathrm{Na}$ seção anterior, caracterizamos a estrutura industrial paulista, privilegiando, em termos analíticos, as configurações setoriais, ou seja, suas principais divisões, embora tenhamos introduzido a distribuição espacial desse conjunto de atividades industriais.

À luz dessa análise, podemos caracterizar a indústria do estado de São Paulo como dividida em 3 grandes regiões produtivas distintas: a região metropolitana de São Paulo, com a sua vasta complexidade, em que preponderam o município de São Paulo e a região do $\mathrm{ABC}$, responsável por $60 \%$ de toda a geração de valor da indústria paulista; a do entorno da metrópole, composta pelas regiões administrativas de Sorocaba, Campinas, São José dos Campos e Santos, que se integra ao espaço produtivo metropolitano de maneira fortemente articulada, com cerca de $30 \%$ do valor adicionado estadual, e as demais regiões do interior do estado, onde, em geral, a agropecuária é a base motora da indústria, e que representa apenas $10 \%$ do valor adicionado pela indústria paulista.

Dada a importância que a região metropolitana de São Paulo (e, em especial, a região do $\mathrm{ABC}$ ) possuem na atividade industrial paulista e brasileira e, particularmente, no debate sobre a perda de seu dinamismo, elas serão analisadas aqui de maneira um pouco mais detalhada.

\section{IV.1 Região metropolitana de São Paulo}

No que se refere aos aspectos regionais, ao contrário do que se crê comumente, nota-se que é forte a presença da atividade industrial na região metropolitana de São Paulo, que mantém alta sua participação relativa na produção industrial do estado, com $60 \%$ do valor adicionado. E mais, é marcante a presença nesta região daquelas divisões que formam a matriz dinâmica da indústria de transformação nacional: os complexos metalmecânico, eletro-eletrônico e de comunicações e petroquímico (borracha e material plástico).

Em nítido contraste com as afirmações sobre um movimento irreversível de esvaziamento econômico da região metropolitana de São Paulo, observamos que a participação do município de São Paulo é extremamente importante, em qualquer variável analisada (um terço de todo o valor adicionado pela indústria paulista e do pessoal ocupado estão na capital), enquanto a participação do $\mathrm{ABC}$ e dos demais municípios da RMSP é mais importante em termos de valor adicionado que em pessoal ocupado e em número de unidades instaladas.

A estrutura industrial da região metropolitana mostra-se bastante diversificada e, pelo seu peso, é semelhante à do total do estado. As diferenças marcantes são a menor participação do setor de alimentos e bebidas (dada sua importância para o interior do estado), e a maior participação do de edição, impressão e reprodução de gravações.

\section{IV.2 Região do $A B C$}

A região do $\mathrm{ABC}$, que concentra mais de $13 \%$ do valor adicionado pela indústria paulista ${ }^{8}$, com-

\footnotetext{
8 É importante ressaltar que, pelos dados do Valor Adicionado Fiscal da Secretaria da Fazenda do Estado de São Paulo, a participação dessa região no total do estado, desde 1985 até 1996 , variou de $13 \%$ a 16\%, ou seja, não houve uma alteração expressiva na participação da região na indústria do estado, ao longo desses 11 anos.
} 
Gráfico 1 - Valor adicionado e pessoal ocupado por divisão da indústria, na região metropolitana de São Paulo, em 1996

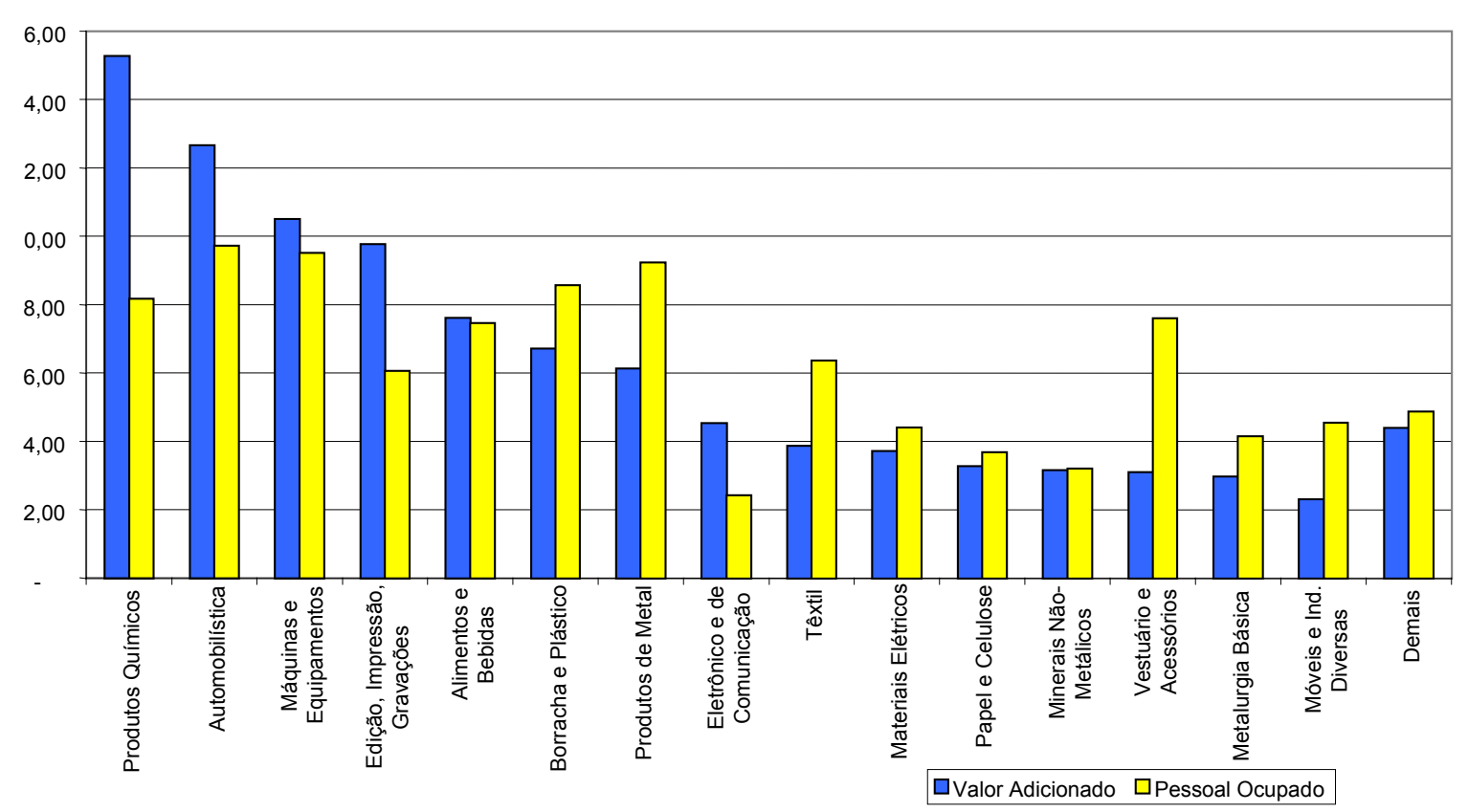

Fonte: Fundação SEADE. Pesquisa da Atividade Econômica Paulista. PAEP.

preende sete municípios - Santo André, São Bernardo do Campo, São Caetano do Sul, Diadema, Mauá, Ribeirão Pires e Rio Grande da Serra -, e sua indústria está basicamente concentrada na produção automobilística, que inclui o setor de autopeças, tanto em valor adicionado quanto em pessoal ocupado. Além da sua importância na região, o valor adicionado desta divisão, no ABC, corresponde a quase metade do total gerado pela indústria automobilística no estado.

Apesar disso, sua estrutura compreende uma variada atividade industrial, sendo algumas tributárias da indústria automobilística, outras ligadas ao potencial de consumo da região. No primeiro caso, com participação expressiva no valor adicionado, estão as divisões de máquinas e equipamentos, produtos de borracha e plástico, produtos de metal (exceto máquinas e equipamentos) e metalurgia básica, também fazendo parte do complexo automobilístico, contribuindo com peças, componentes e insumos.

É também expressiva a participação da indústria química no $\mathrm{ABC}$, responsável por mais de $15 \%$ do valor adicionado e $10 \%$ dos empregos na região. Estudos recentes apontam para a complementaridade entre as indústrias petro- química, de embalagens e de alimentos, ligadas ao alto poder de consumo do mercado local.

$\mathrm{O}$ município com maior número de empregos industriais no ABC é o de São Bernardo do Campo, principalmente na divisão de veículos automotores, mas também em produtos quími$\cos$, máquinas e equipamentos. Em seguida aparecem os municípios de Diadema (borracha e plástico, produtos de metal e máquinas e equipamentos), Santo André (metalurgia básica, borracha e plástico e veículos automotores) e São Caetano do Sul (veículos automotores). Um pouco menores mas também importantes são os municípios de Mauá (veículos automotores, produtos químicos e minerais não-metálicos) e Ribeirão Pires (produtos de metal e outras indústrias).

Os indicadores de tecnologia da indústria do ABC mostram-se bastante superiores aos da média estadual, inclusive para os segmentos de baixa intensidade tecnológica (AGÊNCIA DE DESENVOLVIMENTO DO ABC, 2000), o que, se por um lado parece indicar maior competividade das empresas locais, por outro, também tem significado um menor número de pessoas ocupadas. Como o desempenho inovador está centrado nas grandes empresas (onde os postos de trabalho são 
Gráfico 2 - Distribuição do valor adicionado e do pessoal ocupado, por divisão da indústria, na região do ABC, em 1996

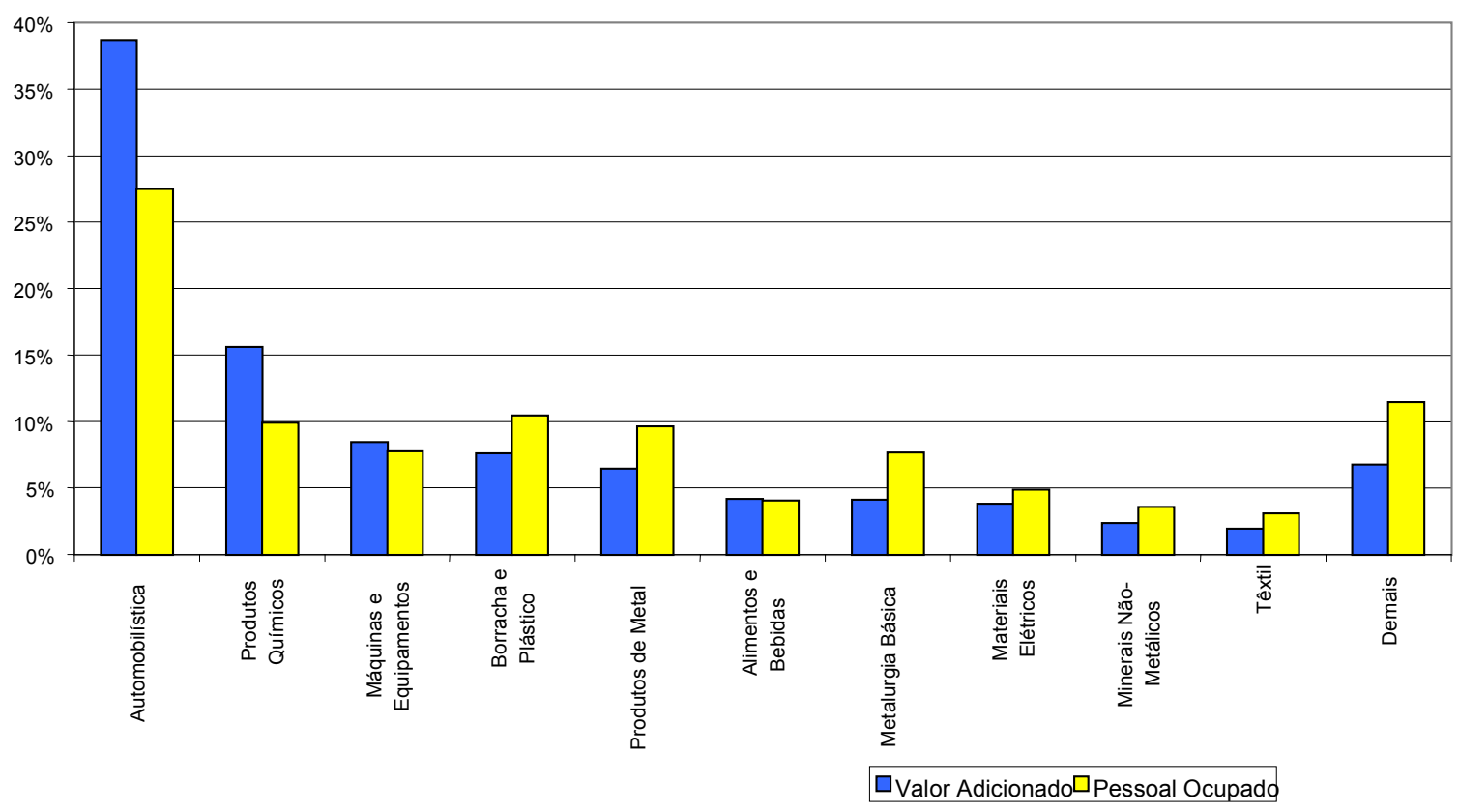

Fonte: Fundação SEADE. Pesquisa da Atividade Econômica Paulista. PAEP.

de melhor qualidade), há uma diminuição desses postos de trabalho e um crescimento daqueles mais precários, principalmente no setor de serviços.

Esses dados, aliados aos da complexa estrutura da região, indicam que a questão central da indústria da região do $\mathrm{ABC}$ não está centrada na ausência de ganhos de competividade, e, conseqüentemente, de crescimento econômico, mas da incapacidade da atividade industrial estar gerando empregos, sobretudo os de qualidade.

\section{A DINÂMICA DOS INVESTIMENTOS IN- DUSTRIAIS NOS ANOS 90}

Neste item vamos utilizar para a análise da dinâmica dos investimentos industriais no estado de São Paulo as duas fontes disponíveis ${ }^{9}$ para verificar a manutenção das características descritas nas seções anteriores ou indicar indícios de modificações nas condições encontradas para o período 1990-1996.

9 Há duas fontes de informação para verificar os investimentos feitos na atividade industrial, no Estado de São Pau-
A PAEP perguntou às empresas multilocais se elas abriram novas unidades produtivas nesse período, e, em caso afirmativo, em qual região; as respostas estão apresentadas nas tabelas 4 e 5 . Por elas, verifica-se que as empresas de pequeno porte foram as que mais abriram novas unidades no período, embora com participações modestas, seja no valor adicionado, seja no pessoal ocupado. As grandes empresas, com pequena participação no número de unidades, apresentam a grande maioria da participação em valor adicionado e em pessoal ocupado. Com relação ao total da indústria, nota-se que, apesar da importância relativa das empresas de pequeno porte, apenas pouco mais de $1 \%$ dessas empresas abriu novas unidades entre 1990 e 1996, enquanto quase 1/3 das grandes abriu novas unidades. Quando a análise é feita sob a ótica do valor adicionado ou do pessoal ocupado, é marcante a participação das grandes empresas, mesmo em relação à sua participação no total da indústria.

lo: o Guia de Investimentos do Estado de São Paulo e a Pesquisa da Atividade Econômica Paulista (PAEP). 
Tabela 4 - Distribuição do número de unidades, pessoal ocupado e valor adicionado das empresas que instalaram novas unidades entre 1990 e 1996, e participação no total da indústria paulista, segundo faixa de pessoal ocupado, no estado de São Paulo, em 1996 (em \%)

\begin{tabular}{|c|c|c|c|c|c|c|}
\hline \multirow{2}{*}{$\begin{array}{l}\text { Faixas de } \\
\text { pessoal } \\
\text { ocupado }\end{array}$} & \multicolumn{3}{|c|}{$\begin{array}{l}\text { Empresas que instalaram novas unidades entre } \\
\qquad 1990 \text { e } 1996\end{array}$} & \multicolumn{3}{|c|}{ Participação no total da indústria } \\
\hline & $\mathrm{N}^{\circ}$ de empresas & Valor adicionado & $\begin{array}{l}\text { Pessoal } \\
\text { ocupado }\end{array}$ & $\begin{array}{l}\mathrm{N}^{\circ} \text { de } \\
\text { empresas }\end{array}$ & Valor adicionado & $\begin{array}{l}\text { Pessoal } \\
\text { ocupado }\end{array}$ \\
\hline 5 a 29 & 28,2 & 0,6 & 1,4 & 1,2 & 1,7 & 1,3 \\
\hline 30 a 99 & 29,1 & 2,8 & 5,5 & 5,3 & 6,4 & 5,1 \\
\hline 100 a 249 & 17,6 & 5,8 & 9,5 & 10,0 & 10,7 & 9,6 \\
\hline 250 a 499 & 9,7 & 9,5 & 10,7 & 15,0 & 17,7 & 13,5 \\
\hline 500 e mais & 15,4 & 81,3 & 72,9 & 27,6 & 31,4 & 31,5 \\
\hline Total & 100,0 & 100,0 & 100,0 & 3,1 & 22,5 & 15,9 \\
\hline
\end{tabular}

Fonte: Fundação SEADE. Pesquisa da Atividade Econômica Paulista. PAEP.

Chama a atenção a distribuição regional dessas unidades: contrariamente ao que é voz corrente, é a região metropolitana a localização preferencial das unidades das empresas que abriram novas unidades locais, seguida pelo interior do estado de São Paulo e, mais atrás, os outros estados do Brasil. O exterior aparece com participação muito pequena, embora o Mercosul tenha apresentado quase o dobro das implantações que o restante do exterior.
Quando se analisam esses dados por porte de empresas, verifica-se que as grandes empresas têm um comportamento bastante diferenciado, privilegiando a implantação de unidades locais no interior de São Paulo e em outros estados, vindo a RMSP a seguir (embora com uma participação expressiva). Esses dados indicam que as grandes empresas abrem novas unidades em muitas regiões, de São Paulo e do Brasil, enquanto as de porte médio e pequeno priorizam o estado de São Paulo e, sobretudo, a RMSP.

Tabela 5 - Distribuição das unidades industriais implantadas pelas empresas da indústria paulista, por região de implantação, segundo faixa de pessoal ocupado, no estado de São Paulo, em 1996 (em \%)

\begin{tabular}{|c|c|c|c|c|c|c|}
\hline \multirow{2}{*}{$\begin{array}{l}\text { Faixas de } \\
\text { pessoal } \\
\text { ocupado }\end{array}$} & \multicolumn{5}{|c|}{ Regiões de implantação das unidades locais } & \multirow{2}{*}{ Total } \\
\hline & $\begin{array}{l}\text { Metropolitana de } \\
\text { São Paulo }\end{array}$ & $\begin{array}{c}\text { Interior de São } \\
\text { Paulo }\end{array}$ & $\begin{array}{l}\text { Outros } \\
\text { estados }\end{array}$ & Mercosul & Exterior & \\
\hline 5 a 29 & 62,7 & 33,6 & 3,7 & - & - & 100,0 \\
\hline 30 a 99 & 48,4 & 43,5 & 8,1 & - & - & 100,0 \\
\hline 100 a 249 & 40,9 & 41,2 & 17,2 & - & 0,7 & 100,0 \\
\hline 250 a 499 & 26,6 & 43,3 & 27,5 & 2,6 & - & 100,0 \\
\hline 500 e mais & 23,6 & 34,5 & 32,1 & 6,1 & 3,6 & 100,0 \\
\hline TOTAL & 43,9 & 38,8 & 15,0 & 1,4 & 0,8 & 100,0 \\
\hline
\end{tabular}

Fonte: Fundação SEADE. Pesquisa da Atividade Econômica Paulista. PAEP.

O panorama oferecido pelos dados da PAEP retrata de maneira adequada a evolução da estrutura industrial paulista entre 1990 e 1996; ficam, porém, interrogações sobre o que pode ter ocorrido no período seguinte. Como sabemos, não dispomos de pesquisas para o período 1996-1999 com a mesma abrangência e metodologia adotada pela PAEP ${ }^{10}$. Em vista disso, vamos utilizar como

10 Está em curso a nova PAEP de 2002 (início em abril), para o ano-base 2001, financiada pela FAPESP, Ministério da Educação, Ministério da Ciência e Tecnologia e Secretaria Estadual de Planejamento, incluindo os dados referentes ao setor de serviços. 
uma proxy os dados do Guia de Investimentos do Estado de São Paulo (SEADE, s/d) para a cobrir a ausência de dados da PAEP para o período 19971999.

Para efeitos de análise, vamos considerar que a distribuição dos investimentos por divisões da indústria e por regiões permite verificar a manutenção das características descritas nas seções anteriores ou indicar modificações nas condições encontradas para o período 1990-1996.

Os investimentos do período 1995-98 chegam a cerca de US $\$ 70$ bilhões, enquanto para o ano de 1999 estavam previstos cerca de US\$14 bilhões. Os investimentos na atividade industrial, no primeiro período, somavam US\$34 bilhões, ou 49\% do total, enquanto para o ano de 1999 somavam US $\$ 5,6$ bilhões ( $40 \%$ do total). A região metropolitana de São Paulo encabeça a lista das regiões do estado que receberam o maior volume de investimentos industriais: US\$8,9 bilhões no período 1995-1998 (26,3\% do total do período) e US\$2,5 bilhões em 1999 (44,3\% do total do ano).

A localização dos novos investimentos das empresas multinacionais tem privilegiado regiões caracterizadas pela concentração de recursos humanos qualificados, centros de pesquisas, universidades e um tecido industrial formado por empresas estrangeiras ligadas a setores intensivos em conhecimento e tecnologia. Por isso, é sintomático que as regiões administrativas de Campinas e de São José dos Campos apresentem-se como as de maior volume de investimentos do interior, nos dois períodos considerados: $24 \%$ e $19 \%$ do total de investimentos foram direcionados para a RA de Campinas nos períodos 1995-98 e 1999, respectivamente, e $22 \%$ e $23 \%$ dos investimentos foram direcionados, nos mesmos períodos, para a RA de São José dos Campos. Se adicionarmos a essas regiões administrativas as de Santos e de Sorocaba, verifica-se que esse conjunto territorial (RMSP e seu entorno) concentrava, no período 1995-1998, 84\% dos investimentos industriais do estado, enquanto para o ano de 1999 esse percentual subiu para $91 \%$.

A partir da distribuição espacial das intenções de investimentos diretos externos é possível verificar, de um lado, a confirmação do movimento de "desconcentração concentrada" da atividade industrial no estado, beneficiando, inclusive, diversos municípios da região metropolitana, principalmente Guarulhos, São Bernardo, São Caeta- no e Barueri e, de outro, a presença de vantagens locacionais associadas aos setores intensivos em tecnologia e conhecimento, exemplificados pelos exemplos de Campinas e São José dos Campos.

\section{CONCLUSÕES}

A análise sobre a evolução da indústria do estado de São Paulo permite apontar algumas conclusões provisórias importantes e questões que devem merecer estudos mais aprofundados. Em primeiro lugar, lida à luz da literatura internacional discutida na primeira parte deste artigo, a experiência recente de São Paulo revela um perfil complexo, nem sempre virtuoso e coerente como a teoria é apresentada. Assim, não é possível assimilar as transformações industriais analisadas ao movimento de constituição de uma global city ou mesmo de uma city region, mesmo valorizando as mudanças qualitativas apontadas no trabalho relativas às indústrias intensivas em conhecimento e tecnologia, menos expressivas em termos de valor adicionado e mais na localização dos novos investimentos nas regiões de Campinas e São José dos Campos.

Como procuramos demonstrar, estão ausentes alguns dos componentes considerados estruturantes pelos autores. Concretamente, não parece haver elementos para sustentar uma lógica de acumulação pós-fordista ou flexível, mesmo se aceitamos a idéia de estarmos em pleno processo de transição do modelo industrial. De maneira breve, a hipótese da existência de um modelo de acumulação flexível supõe a existência de uma dinâmica econômica fundada numa imagem estilizada e fortemente normativa sobre o papel das novas tecnologias e o papel das redes de conhecimento, que inexiste no caso estudado.

O papel reservado ao Estado nacional, nas análises dessa corrente, é secundário, já que as city regions articulam-se globalmente, bastando para elas que se façam arranjos de governança que garantam os padrões de competividade das regiões e minimizem os efeitos perversos decorrentes da globalização sobre a geografia social das regiões. Como se vê, a política macroeconômica passa ao largo dessa teoria. Assim, parece-nos bastante problemático analisar a trajetória da indústria paulista abstraindo as características históricas específicas e as características da política macroeconômica adotada pelo governo central.

Em segundo lugar, diferentemente do que apre- 
goam as análises sobre a transformação de São Paulo numa metrópole de serviços, os dados apontam para uma transformação qualitativa da indústria no sentido apontado por Pierre Veltz (1996; 2000). Novamente, não se trata aqui de ignorar a abundante literatura internacional e crescente discussão brasileira sobre o papel dos chamados novos serviços, em especial os chamados tradables, ou seja, comercializáveis à distância. Porém, mesmo reconhecendo o crescimento dos serviços, seja porque parte expressiva parece pertencer à categoria de "serviços produtivos", seja porque há os conhecidos problemas de mensuração de sua produtividade, acreditamos que a hipótese de que São Paulo tornou-se uma cidade global na medida em que se tornou uma metrópole de serviços carece de sustentação empírica adequada.

$\mathrm{O}$ argumento essencial da nossa perspectiva é que mesmo aceitando a existência de uma dinâmica regional que abre espaço para novas metrópoles, que seriam os casos de Curitiba e Belo Horizonte, essas novas economias de aglomeração não só dependem da interação entre indústria e serviços, como ocorrem num macroespaço limitado.

A conclusão é que há uma desconcentração limitada, que não alterou até o momento substantivamente as posições relativas das principais metrópoles, assim como há um movimento de reconcentração regional relacionado às novas vantagens locacionais ligadas à infra-estrutura de telecomunicações, pesquisa científica e tecnológica, recursos humanos qualificados, redes de fornecedores etc. Ao nosso ver, parece prematuro (e indevido) falar na superação da indústria pelos serviços, embora essa questão deva merecer maior atenção na agenda de pesquisa.

Parece-nos que a atual renovação industrial em São Paulo está sendo possível graças à articulação de um conjunto de inovações produtivas e tecnológicas e graças à crescente integração com os serviços (sobretudo os produtivos e mais especializados), que vem provocando alterações em toda a estrutura da indústria, mesmo a mais tradicional. Em um processo que começou a intensificar-se em meados dos anos 80 , integrou inovações tecnológicas, desenvolveu processos de ajuste e de reestruturação produtiva, essa nova manufatura, intensiva em capital e crescentemente baseada em redes de competências e fluxos de conhecimento, é fonte de melhorias contínuas nos índices de produtividade e de salários superiores à média de setores mais tradicionais.

Mesmo indústrias de corte tradicional, como a têxtil, foram atingidas pelas mudanças estruturais por que a indústria vem passando nos últimos anos, dando origem a setores extremamente avançados, intensivos em capital. Em contraste com seu perfil tradicional - uma indústria intensiva em trabalho - surgiram segmentos com grande difusão tecnológica e dependentes de mão-de-obra qualificada e que, por isso mesmo, permanecem ativos, e não só na RMSP, mas mesmo nos países e regiões mais avançadas do globo.

Paralelamente a essa reestruturação, que entendemos profunda, permanecem indústrias de corte tradicional, como a de confecções, de pequeno porte, difusa pelo território metropolitano (em especial na capital), intensiva em mão-de-obra (é a maior empregadora do município de São Paulo), mas também reorientada para novos produtos e processos, atualizada com as novas tendências nacionais e internacionais da moda (KONTIC, 2001).

A explicação da permanência de muitas empresas no estado de São Paulo, em que pesem os altos incentivos econômicos oferecidos por outras regiões do país, pode ser encontrada na valorização da infra-estrutura e da malha de conexões ali existente, em detrimento de regiões abundantes em mão-de-obra não-qualificada.

A análise desenvolvida nas seções anteriores mostrou que dificilmente algumas afirmações bastante propagadas, como o esvaziamento da região metropolitana de São Paulo e a desconcentração da indústria em direção ao setor terciário e ao interior e outras regiões do país, encontram sustentação nos dados empíricos disponíveis sobre sua evolução nos anos noventa. Como demonstramos, a indústria continua tendo um papel fundamental na dinâmica econômica do estado, sobretudo na RMSP (e mesmo na capital e na região do $\mathrm{ABC}$ ).

De fato, o papel da região metropolitana de São Paulo ainda continua expressivo, uma vez que gera $60 \%$ da riqueza produzida pela indústria paulista, cuja estrutura complexa continua respondendo pelo pólo dinâmico da indústria nacional. Os setores mais intensivos em conhecimento (equipamentos de informática, material eletrônico e equipamentos de automação) têm pequena importância na estrutura regional, mas representam 
parcela substantiva desta indústria, seja em relação ao estado, seja em relação ao país. As indústrias tidas como tradicionais (alimentos, têxteis e vestuário), em que pese a atratividade de outras unidades da federação, ainda têm uma expressiva participação na indústria paulista, em valor adicionado (para a de alimentos) e em pessoal ocupado.

Quanto à região do $\mathrm{ABC}$, é importante evitar a idéia (muito presente, sobretudo na mídia) de "desindustrialização", pois ela continua com uma participação importante na estrutura industrial do estado, sobretudo nos setores mais intensivos em capital. A maior incidência de indústrias com grande conteúdo tecnológico na região, atestada pelas análises da Agência de Desenvolvimento do $\mathrm{ABC}$, com base nos dados da PAEP, confere um poder de reestruturação das empresas industriais, permitindo a aquisição de vantagens competitivas; esse processo, contudo, pressiona a mão-de-obra, limitando os postos de trabalho de melhor qualificação, e suprimindo os de menor qualificação, que são absorvidos apenas em parte pelo setor serviços.

Vale lembrar que o município de São Paulo, tido por muitos como praticamente dedicado à produção de serviços, ainda responde, sozinho, por $1 / 3$ da produção industrial do estado, com destaque para os setores intensivos em conhecimento. É o caso expressivo da divisão de edição e impressão, que é o que mais agrega valor na estrutura industrial do município, e que representa $2 / 3$ dessa divisão no estado. No entanto, deve-se ressaltar que não é apenas nos setores mais modernos da indústria que a importância da capital está presente, pois o setor de confecção e artigos do vestuário representa $58 \%$ do pessoal ocupado da divisão no estado e $73 \%$ do seu valor adicionado. O papel importante da atividade industrial de São Paulo já foi detectado pela Secretaria Municipal de Planejamento, que lhe reserva papel central no novo Plano Diretor que está em elaboração.

Quando se se refere à indústria do interior do estado, deve-se sempre ter em conta que ela se limita quase exclusivamente a regiões que circundam a região metropolitana, formando com ela um espaço produtivo ampliado e integrado. A interiorização do desenvolvimento não é disseminada pela totalidade do território paulista, mas limitada às regiões que já possuíam, desde o início da industrialização do estado (cf. NEGRI, 1988;
CANO, 1997), as condições iniciais de desenvolvimento industrial (sobretudo aquelas com concentração do capital cafeeiro) e que estivessem articuladas, através de infra-estrutura adequada, à região metropolitana de São Paulo, excluindo as demais regiões do interior deste complexo industrial. Assim, a industrialização dessas regiões não deve ser entendida como uma alternativa à da RMSP, mas como uma integração ao espaço produtivo da metrópole. Ao analisar-se a tendência dos investimentos industriais em São Paulo, verifica-se uma grande probabilidade de manutenção dessa configuração espacial, privilegiando as áreas em que a indústria paulista mostra-se mais dinâmica, excluindo as demais áreas do interior paulista.

Finalmente, devemos considerar três aspectos principais - e problemáticos - decorrentes da evolução da indústria paulista, na década de noventa: em primeiro lugar, ao deixar-se as decisões de investimento em plantas industriais ao sabor do mercado, a tendência à concentração num espaço produtivo amplo, mas limitado, excluindo vastas áreas do território paulista, parece ser inexorável. Assim como pode-se ver na fundamentação teórica, sem uma política de desenvolvimento de caráter supra-regional (ou seja, um Estado nacional que tenha uma política industrial e regional), não se pode extrair, para a sociedade, as potencialidades que os processos de reestruturação produtiva oferecem.

Em segundo lugar, é clara a redução na capacidade de geração de empregos, sobretudo nas indústrias que passaram por processos de reestruturação produtiva: a queda da participação de São Paulo em relação ao pessoal ocupado na indústria brasileira, acompanhada da manutenção de sua participação na produção, nos últimos 12 anos, mostra o quanto a força de trabalho vem pagando pela manutenção da atividade econômica. Devese lembrar que, ao terceirizar parte de suas atividades não-centrais para empresas de serviços, muitas vezes formadas a partir de funcionários demitidos pelas indústrias ${ }^{11}$, a indústria elimina postos

\footnotetext{
11 Veja-se a respeito a Pesquisa da Atividade de Serviços do ABC - PASSE -, realizada pelo Instituto Superior de Ensino de São Caetano do Sul (IMES) para a Agência do Desenvolvimento do ABC, de 2001 (PAMPLONA \& MIAIDARA, 2001): $27 \%$ das empresas de serviços da região nasceram da terceirização de atividades antes executadas dentro das indústrias.
} 
de trabalho que possuem relações formais, com carteira assinada, e bem-remunerados. As ocupações que são criadas no setor de serviços, por sua vez, têm um vínculo quase sempre precário e, além de serem caracterizadas por salários mais baixos que na indústria, criam menos postos de trabalho que os desmobilizados no secundário.

Em último lugar, deve-se atentar para o reforço das vantagens comparativas das regiões mais dinâmicas. Neste caso, políticas de atratividade de indústrias que tenham um caráter puramente fiscal, ou seja, determinantes de redução de preços das mercadorias, podem não ser suficientes, caso o objetivo seja a atração de setores mais dinâmicos, nos quais a concorrência dá-se por outros fatores que não os preços. Assim, os incentivos fiscais, em regiões com grandes vantagens comparativas, configuram um desperdício do dinheiro público, enquanto para regiões menos favorecidas ele só trará benefícios a empresas que tenham processos produtivos desatualizados ou intensivos em mão-de-obra, e que não necessitam de uma densa rede de empresas que possibilite o aprendizado e o desenvolvimento tecnológico e do mercado de trabalho.

Ao longo deste trabalho procuramos apresentar argumentos para que dois caminhos igualmente perigosos não fossem seguidos porque podem conter perigosas armadilhas.

Em um deles, abre-se espaço para a ocorrência do novo absoluto: já não há mais atividade industrial na RMSP (ou há somente um resíduo de um passado distante, já apagado da memória metropolitana contemporânea), o setor terciário com- põe a metrópole dos anos 90 , conectada pela tecnologia da informação à uma rede inteligente e integrada de cidades globais (cf. MEYER, 2000a) ${ }^{12}$.

Em outro, o fato de acreditar que uma inevitável decadência da atividade industrial levará ao próprio fim da economia metropolitana (já que o setor terciário, por si só, não será capaz de conferir a dinâmica necessária à economia da RMSP), elimina-se a possibilidade de transformação da indústria.

Precisamos de mais estudos para conhecer melhor o significado e a profundidade das mudanças em curso, para saber o que é continuidade ou metamorfose e o que é verdadeiramente novo. Esse esforço analítico deve ter como horizonte identificar janelas de oportunidade para ação coletiva que evitem o risco permanente de uma rendição incondicional ao que se apresenta como novo.

O desafio colocado, portanto, não está nos riscos da "desindustrialização" do $\mathrm{ABC}$ ou da região metropolitana de São Paulo, nem em estimular isenções fiscais, mas sim em desenhar políticas regionais inovadoras, voltadas não só para a criação de condições sistêmicas favoráveis à competividade das empresas, mas também para estimular o emprego. Esse desafio pode ser sintetizado da seguinte forma: a inserção das várias regiões, no momento, passa por uma escolha entre submeter-se passivamente às pressões da economia mundial ou engajar-se ativamente para tirar benefícios da globalização.

Recebido em 29 de outubro de 2001. Aprovado em 2 de abril de 2002.

Miguel Matteo (mimatteo@seade.gov.br) é analista da Fundação SEADE e doutorando em Economia na Universidade Estadual de Campinas (UNICAMP).

Jorge Ruben Biton Tapia (bitapia@eco.unicamp.br) é Doutor em Ciências Sociais pela Universidade Estadual de Campinas e Professor do Departamento de Política e História Econômica da Instituto de Economia da Universidade Estadual de Campinas (UNICAMP).

\footnotetext{
12 Ver também as pesquisas em andamento no Centro de Estudos da Metrópole (CEM), coordenadas por Regina M. P. Meyer e Marta D. Grostein, no Laboratório de Urbanismo da Metrópole, da Faculdade de Arquitetura de Urbanismo da USP e do CEBRAP. Em sua página na internet, Meyer afirma sobre os ciclos da RMSP, que "primeiro pode ser
}

caracterizado como precário e incompleto, remanescente do ciclo industrial; o segundo, adaptado e qualificado, comprometido com a nova fase e com os novos programas do estágio metropolitano pós-industrial e terciário (serviços)" (MEYER, 2000b). 


\section{REFERÊNCIAS BIBLIOGRÁFICAS}

AMIN, A. \& ROBINS, K. 1994. El retorno de las economias regionales. Geografía mítica de la acumulación flexible. In : LIPIETZ, A. \& BENKO, G. (dirs.). Las regiones que ganan. Valência : Alfons el Magnànim.

ARAÚJO, M. F. I. 2000. Mapa da estrutura industrial e comercial do estado de São Paulo. São Paulo em perspectiva, v. 13, n. 1-2, p. 40-52, mar.

2001. Impactos da reestruturação produtiva sobre a região metropolitana de São Paulo no final do século $X X$. Campinas. Tese (Doutorado em Economia). Instituto de Economia, Unicamp.

CANO, W. 1988 A interiorização do desenvolvimento econômico do Estado de São Paulo (1920-1980). São Paulo : Fundação SEADE/ Unicamp.

. (coord.). 1992. São Paulo no limiar do século XXI. São Paulo : Fundação SEADE/ Unicamp.

1997. Concentração e desconcentração econômica regional no Brasil. Economia e sociedade, Campinas, n. 8, p. 101-141, jun.

CASTELLS, M. 1996. La ciudad informacional. Madrid: Alianza.

COMPANS, R. 1999. O paradigma das global cities nas estratégias de desenvolvimento local. Revista brasileira de estudos urbanos $e$ regionais, São Paulo, n. 1, maio.

DUNFORD, M. \& KAFKALAS, G. 1992. Cities and Regions in the New Europe : the GlobalLocal Interplay and Spatial Development Strategies. London : Belhaven.

FRIEDMANN, J. \& WOLF, G. 1982. World City Formation: an Agenda for Research and Action. International Journal of Urban and Regional Research, Oxford, n. 6, p. 309-344.

FRIEDMANN，J. 1996. The World City Hipothesis. Development and Change, n. 4, p. 12-50.

HALL, P. 1966. The World Cities. London : Weidenfeld and Nicholson.

HALL, T. \& HUBBARD, P. (eds.). 1998. The Entrepreneurial City. Chichester: Wiley.
KONTIC, B. 2001. Aprendizado e metrópole : a reestruturação produtiva da indústria do vestuário em São Paulo. São Paulo. Dissertação (Mestrado em Sociologia). Faculdade de Filosofia, Letras e Ciências Humanas, Universidade de São Paulo.

LAURIA, M. 1997. Reconstructing Urban Regime Theory : Regulating Urban Politics in a Global Economy. London : Sage.

MATTEO, M. 1990. A dinâmica da localização industrial na área metropolitana de São Paulo. São Paulo. Dissertação (Mestrado em Administração e Planejamento Urbano). Escola de Administração e Economia, Fundação Getúlio Vargas.

MEYER, R. M. P. 2000a. Atributos da metrópole moderna. São Paulo em perspectiva, São Paulo, v. 14, n. 4, p. 3-9, out.-dez.

2000b. Centro de Estudos da Metrópole. Informativo FAU-USP, São Paulo, ano 2, n. 1, dez. www.usp.br/fau/informa/infor 18-02. htm : 25.nov.2001.

NEGRI, B. 1988. A interiorização da indústria paulista (1920-1980). Col. Economia Paulista, v. 2. São Paulo : Fundação Sistema Estadual de Análise de Dados/Unicamp.

PACHECO, C. A. 1996. A questão regional brasileira pós-1980 : desconcentração econômica e fragmentação da economia nacional. Campinas. Tese (Doutorado em Economia). Instituto de Economia, Universidade Estadual de Campinas.

PAMPLONA, J. B. \& MIAIDARA, P. L. 2001. Primeira análise dos resultados da Pesquisa da Atividade do Setor de Serviços Empresariais do Grande ABC (PASSE/ABC). Santo André : Agência de Desenvolvimento do Grande $\mathrm{ABC}$.

PIORE, M. J. \& SABEL, C. F. 1984. The Second Industrial Divide. New York : Basic Books.

SASSEN, S. 1991. The Global City : New York, London, Tokyo. Princeton : Princeton University Press.

1994. Cities in a World Economy. Sociology for a New Century. Thousand Oaks : Pine 
Forges Press.

1999. The Impact of the Internet on Sovereignty Real and Unfounded Worries. Paper presented at the conference "Internet and International Systems. Information Technology and American Foreign Policy Decision-Making", occurred in Washington. Digit.

SCOTT, A. 1996. Regional Motors of the Global Economy. Futures, London, v. 28, n. 5, p. 391411.

SCOTT, A., AGNEW, J., SOJA, E. W. \& STORPER, M. 1999. Global City Regions. Paper presented on the Global City Regions Conference, at the University of California, in
Los Angeles.

SEADE. 2000. Pesquisa da atividade econômica paulista : uma metodologia de produção de dados e conhecimento. São Paulo em perspectiva, v. 13, n. 1-2, p. 23-39.

SMITH, D. J. S. \& TOPIC, S. C. (eds.). 1999. States and Sovereignty in the Global Economy. London : Routledge.

VELTZ, P. 1996 Mondialisation, villes et territoires : l'économie d'archipel. Paris : Presses Universitaires de France.

.2000. Le noveau monde industriel. Paris : Gallimard.

\section{OUTRAS FONTES}

AGÊNCIA DE DESENVOLVIMENTO DO ABC. 2000. A atividade econômica nos anos 90 no grande $A B C$. Reestruturação e inovação na indústria. Caderno de pesquisa n. 2. Santo André : Agência de Desenvolvimento do ABC.

ASSEMBLÉIA LEGISLATIVA DO ESTADO DE SÃO PAULO. 2000. Indústria. Cadernos do Fórum Século XXI, n. 11. www.al.sp. gov.br : março de 2002.
FIESP. s/d. Índice de ocupação. www.fiesp. org.br.

SEADE. s/d. Guia de investimentos do Estado de São Paulo. www.seade.gov.br.

. 1999. PAEP. Registros metodológicos. CD-ROM, versão 1. São Paulo : Fundação Sistema Estadual de Análise de Dados. 